\title{
Analysing the impact of the two most common SARS-CoV-2 nucleocapsid protein variants on interactions with membrane protein in silico
}

\author{
Syeda Tasnim Quayum and Saam Hasan ${ }^{*}$ (1)
}

\begin{abstract}
As the body of scientific research focusing on the severe acute respiratory syndrome coronavirus 2 or SARS-CoV-2 continues to grow, several mutations have been reported as very common across the globe. In this study, we analysed the SARS-CoV-2 nucleocapsid protein (N protein) with respect to the widely observed 28881-28883 GGG to AAC variant. One of the major functions of the SARS-CoV-2 nucleocapsid protein is virion packaging through its interactions with the membrane protein ( $M$ protein). Our goal was to investigate, using in silico studies, the interaction between the mutant nucleocapsid protein and the $M$ protein and how it differed from that of wild type $\mathrm{N}-\mathrm{M}$ protein interaction. The results showed significant differences in interactions between the two. The mutant protein was predicted to form 3 salt bridges with the M protein, while the wild type only formed 2 . The mutant protein was also predicted to display less temperature sensitivity than its wild type counterpart.
\end{abstract}

Keywords: SARS-CoV-2, Proteomics, N-M protein interactions, N protein

\section{Introduction}

The $204 \mathrm{G}>\mathrm{R}$ and $203 \mathrm{R}>\mathrm{K}$ amino acid substitutions are two of the most commonly observed mutations in the SARS-CoV-2 proteome. Owing to its global distribution, we raise the question whether this is an advantageous mutation that became a stable change over time, or vice versa. To narrow our focus toward a more specific goal, we analysed the effect of these substitutions on the nucleocapsid protein's interactions with the membrane protein, a process vital for virion packaging.

The severe acute respiratory syndrome coronavirus 2 , or SARS-CoV-2, caused COVID-19 pandemic continues to affect the world [11]. As of April 20, 2021, the virus, originating from Wuhan, China, has spread to 227 countries, infecting over 141 million people and leading to over 3 million deaths [30]. Symptom identification and disease management is still proving complicated, with a

\footnotetext{
*Correspondence: saamhasan55@outlook.com
} Dhaka, Bangladesh

\section{Springer Open}

(c) The Author(s). 2021 Open Access This article is licensed under a Creative Commons Attribution 4.0 International License, which permits use, sharing, adaptation, distribution and reproduction in any medium or format, as long as you give appropriate credit to the original author(s) and the source, provide a link to the Creative Commons licence, and indicate if changes were made. The images or other third party material in this article are included in the article's Creative Commons licence, unless indicated otherwise in a credit line to the material. If material is not included in the article's Creative Commons licence and your intended use is not permitted by statutory regulation or exceeds the permitted use, you will need to obtain permission directly from the copyright holder. To view a copy of this licence, visit http://creativecommons.org/licenses/by/4.0/.

multitude of ever-evolving factors such as age dependence, making treatment difficult $[1,2,14,16]$. Meanwhile, a vast volume of research on the virus has accumulated, focussing on the viral genome, proteome, as well as treatment options [5, 9, 22].

A lot of the research has focussed on the presence and distribution of genomic variants. Many of these have been found in isolates from all parts of the world. Genome characterization of SARS-CoV-2 isolates has revealed well over 100 globally distributed mutations [17]. Variants such as the 23403 A to $G$ that causes the 614 D to $G$ mutation in the spike glycoprotein have received a lot of attention [20]. The $\mathrm{N}$ gene has also been the subject of a fair amount of scrutiny $[15,25]$. The 2888128883 GGG to AAC variant has also been observed widely in isolates from across the globe [24].

The two variants in focus occur within the intrinsically disordered region (IDR) of the $\mathrm{N}$ protein. This region has been shown to be involved in liquid-liquid phase 
separation (LLPS), a process that plays a part in RNA packaging. Furthermore, the disordered regions are all known to take part in protein-protein interactions $[8,28$, 29]. Straightaway, this raises the question whether the amino acid substitutions can lead to functional changes, despite the substituted amino acids also being disorder promoting.

In this study, we wished to explore if this common variant can have a potential impact on the interactions between the $\mathrm{N}$ protein and the membrane protein $(\mathrm{M}$ protein), something that has not been widely investigated yet. These interactions are vital for RNA packaging and virion assembly; hence, any factor that has a significant influence on them should be investigated to the utmost, as it may be associated with changes in stability of virion structure and consequently its transmissibility and survival rates.

Here, we explored these interactions by predicting the 3D structures of both the mutant (28881-28883 variant containing) and wild type (accession ID: YP 009724393.1) (Wuhan RefSeq) N-proteins using amino acid sequences. Subsequently, we carried out an in silico docking with M protein (accession ID: YP_009724393.1). This was followed by analysis and comparison of $2 \mathrm{~N}-\mathrm{M}$ complexes. Both the $\mathrm{N}$ and $\mathrm{M}$ proteins are key structural components of the virus [4, 7]. Hence, we hypothesize that any changes in interactions between them could have a potential impact on viral functions. The purpose of this initial study was to analyse and ascertain these differences resulting from the aforementioned multiple nucleotide variant or MNV, in order to identify any advantageous or disadvantageous nature of said variant. Both of these proteins are predicted to exist as multimers in their innate native states (Masters 2019). This was also taken into account when predicting protein 3 dimensional structure and docking.

\section{Methodology}

Protein structure prediction for the $\mathrm{M}$ and both the $\mathrm{N}$ proteins were carried out using Robetta server (https:// robetta.bakerlab.org/) [18]. The structures were refined using 3Drefine (http://sysbio.rnet.missouri.edu/3Drefine/) [6]. The pdb structures obtained from 3Drefine were further refined using Galaxyrefine tool [13] (http://galaxy. seoklab.org/). Structures with the lowest Molprobity, RMSD values and Clash scores were chosen and then further validated using Ramachandran plot analysis. Proteinprotein docking was carried out using Cluspro server (https://cluspro.bu.edu/login.php) [19]. Each of the N proteins (mutant) and (Wuhan reference) were docked separately with the $\mathrm{M}$ protein. The docking results were first visualized using PyMol software (https://pymol.org/2/). For confirmation, the protein-protein interactions between the 2 docked complexes were visualized using separate tools so as to ensure all possible interactions were properly identified. In addition to PyMol version 1.2, PDBSum (http://www.ebi.ac.uk/thorntonsrv/databases/ cgibin/pdbsum) [21], CoCoMaps (https://www.molnac. unisa.it/BioTools/cocomaps/) [27] and Disovery studio visualizer (https://discover.3ds.com/discovery-studiovisualizer-download) were used. Temperature sensitivity of both the mutant and wild type protein complexes were also checked using the Prodigy tool [31].

\section{Results}

The structures of $\mathrm{M}$ and both $\mathrm{N}$-proteins were predicted, refined and validated. The final predicted structure of $\mathrm{M}$ protein has a Molprobity score of 1.736, clash score of 11.7 and RMSD value of 0.290 . Validity of the structures analysed by Ramachandran plot shows $94 \%$ residues residing in most favoured regions, $1 \%$ in disallowed and $4 \%$ in additional acceptable regions. The mutant N-protein has a MolProbity score of 1.660 RMSD value of 0.264 and Clash score of 10.4. Ramachandran plot analysis carried out on the Mutant isolate N-protein showed $92.8 \%$ residues residing in highly favoured regions, $0.6 \%$ in moderately allowed and $0.3 \%$ in disfavoured regions. Wild type N-protein has a MolProbity score of 1.451 RMSD value of 0.236 and Clash score of 8.3. Ramachandran plot analysis carried out on the wild type $\mathrm{N}$ protein showed $91.6 \%$ residues residing in highly favoured regions, $0.0 \%$ in moderately allowed and $0.6 \%$ in disfavoured regions (Fig. 1). After the docking was carried out between the $\mathrm{M}$ and each of the $\mathrm{N}$-proteins, the structures with lowest energy levels and most number of interacting members were chosen. Energy level of Fig. 2A was - 1059.1 KJ with 128 members acting and of Fig. 2B docked complex was - $1221.0 \mathrm{KJ}$ with 57 members. Supplementary files 1 and 2 provide the final PDB structures generated for the mutant-M protein and wild type- $\mathrm{M}$ protein complexes respectively.

Table 1 and Table 2 list all contact residues for each of the N-M docked complexes. Overall, there were 25 amino acid residues from the mutant $\mathrm{N}$-protein that interact with the $\mathrm{M}$, while for the wild type, there are 27 residues. The number of hydrophobic interactions between residues was also higher for the wild type (139), compared to the mutant (104). The binding affinity and dissociation constant $\left(\mathrm{K}_{\mathrm{D}}\right)$ were both lower for the mutant protein. There were also differences in the key residue interactions. For the wild type, there were two salt bridges predicted between the $\mathrm{M}$ and $\mathrm{N}$ proteins (LYS162-ASP341 and LYS162-ASP348). The number of salt bridges observed for the mutant protein was 3, and they involved different residues (ARG42ASP288, ARG146-GLU323, ARG150-GLU323). The number of hydrogen bonds was also higher for the mutant at 15 . The wild type shared 14 hydrogen bonds 


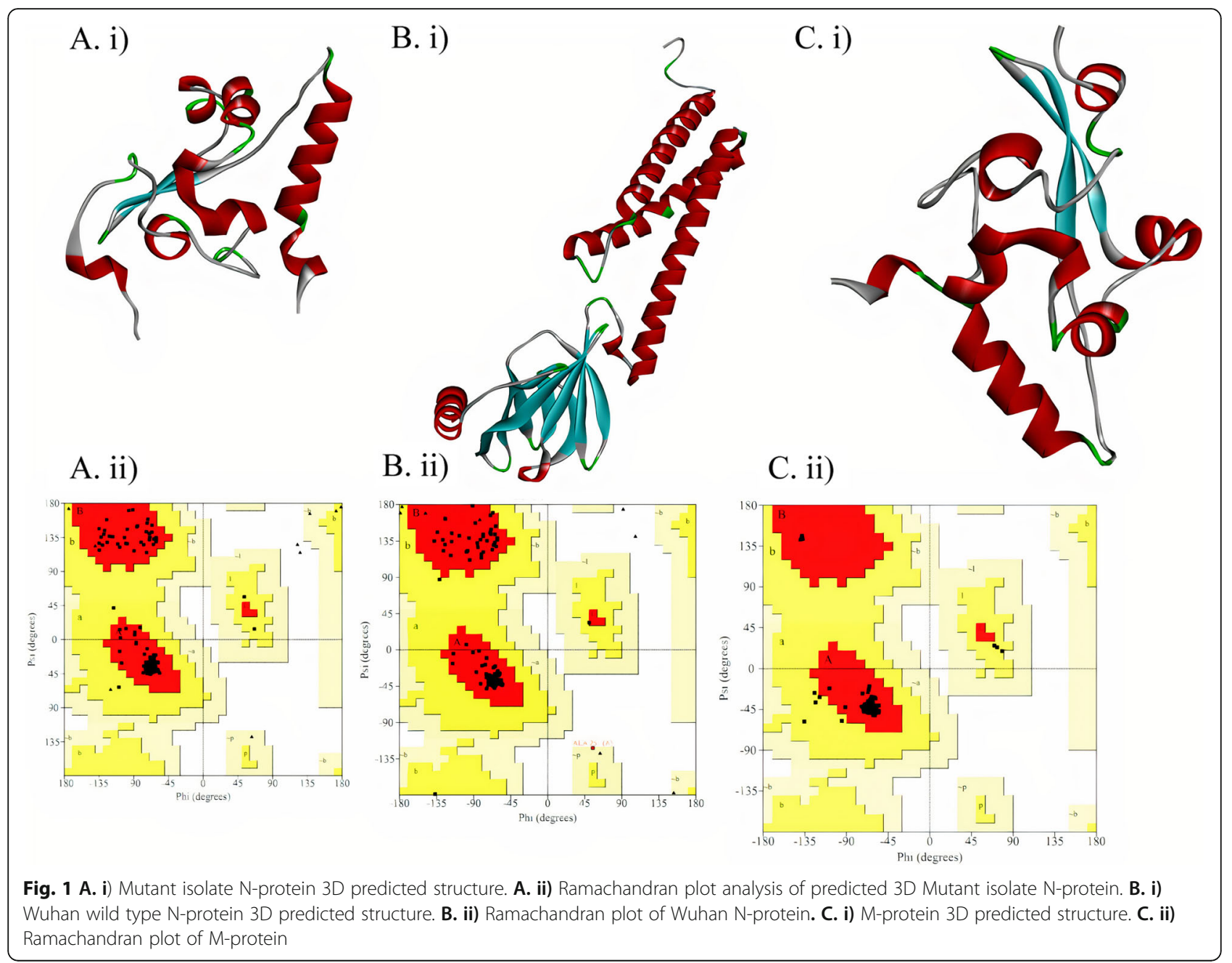

with the M protein. Lastly, the number of non-bonded contacts (Van der Waals forces) was also higher for the mutant (162) than the wild type (134). Other important residues include the Serine at position 318, which was shown to be an interacting residue for both the complexes. The list of major interacting residues is shown in Tables 1 and 2. For size constraints, only the hydrogen bonds and salt bridges are included here. The complete lists can be found in Supplementary Tables $1 \mathrm{~A}$ and $1 \mathrm{~B}$.

Another interesting observation here was the fact that increasing the temperature value affected the two complexes differently. For the mutant protein, a simulation that increased temperature from 25 to $35{ }^{\circ} \mathrm{C}$ resulted in
A

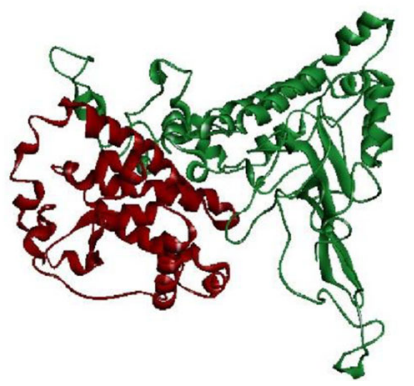

B

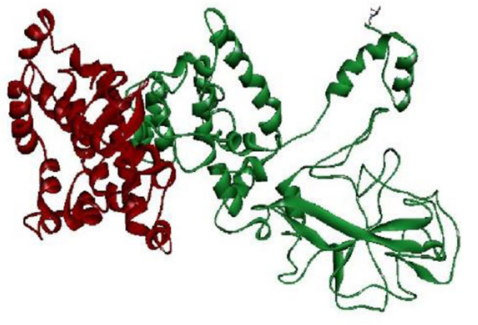

Fig. 2 A Bangladeshi isolate N \& M-protein docking complex. B Wuhan wild type N \&M-protein docking complex 
Table 1 Residues involved in hydrogen bonds and salt bridges between the mutant $\mathrm{N}$ protein and the $\mathrm{M}$ protein

\begin{tabular}{|c|c|c|c|c|c|c|c|}
\hline Bond type & $\begin{array}{l}\text { M protein } \\
\text { atom }\end{array}$ & $\begin{array}{l}M \text { protein } \\
\text { residue }\end{array}$ & $\begin{array}{l}\text { M protein residue } \\
\text { position }\end{array}$ & $\begin{array}{l}\mathrm{N} \text { protein } \\
\text { atom }\end{array}$ & $\begin{array}{l}\mathrm{N} \text { protein } \\
\text { residue }\end{array}$ & $\begin{array}{l}\mathrm{N} \text { protein residue } \\
\text { position }\end{array}$ & Distance \\
\hline Hydrogen bond & $\mathrm{N}$ & ALA & 2 & OE2 & GLU & 323 & 3.04 \\
\hline Hydrogen bond & ND2 & ASN & 41 & $\mathrm{O}$ & ARG & 319 & 3.01 \\
\hline Hydrogen bond & $\mathrm{NE}$ & ARG & 42 & $\mathrm{O}$ & GLN & 283 & 2.9 \\
\hline Hydrogen bond & $\mathrm{NH} 1$ & ARG & 42 & $\mathrm{O}$ & ILE & 320 & 2.71 \\
\hline Hydrogen bond & $\mathrm{NH} 2$ & ARG & 42 & $\mathrm{O}$ & PHE & 286 & 2.81 \\
\hline Hydrogen bond & $\mathrm{NH} 2$ & ARG & 42 & $\mathrm{O}$ & GLY & 287 & 2.66 \\
\hline Hydrogen bond & $\mathrm{NH} 2$ & ARG & 42 & OD1 & ASP & 288 & 2.91 \\
\hline Hydrogen bond & $\mathrm{NH} 2$ & ARG & 44 & OG & SER & 312 & 2.77 \\
\hline Hydrogen bond & $\mathrm{N}$ & ILE & 144 & O & GLY & 284 & 2.8 \\
\hline Hydrogen bond & $\mathrm{N}$ & ARG & 146 & OD1 & ASP & 288 & 3.19 \\
\hline Hydrogen bond & $\mathrm{NH} 1$ & ARG & 146 & OE1 & GLU & 323 & 2.76 \\
\hline Hydrogen bond & $\mathrm{N}$ & GLY & 147 & OE1 & GLU & 290 & 2.84 \\
\hline Hydrogen bond & $\mathrm{NH} 1$ & ARG & 150 & OE2 & GLU & 323 & 2.79 \\
\hline Hydrogen bond & $\mathrm{NH} 2$ & ARG & 150 & OE1 & GLU & 323 & 2.73 \\
\hline Salt bridge & $\mathrm{NH} 1$ & ARG & 42 & OD1 & ASP & 288 & 2.75 \\
\hline Salt bridge & $\mathrm{NH} 1$ & ARG & 146 & OE2 & GLU & 323 & 2.76 \\
\hline Salt bridge & $\mathrm{NH} 2$ & ARG & 150 & OE2 & GLU & 323 & 2.73 \\
\hline
\end{tabular}

a weaker affinity with the $M$ protein. For the wild type, however, there was no discernible difference. This could suggest that the mutant protein is more sensitive to higher temperatures than the wild type. Table 3 summarizes the affinities for the two complexes at different temperatures.

In order to observe whether the mutated residues formed any strong hydrogen bonds, pymol was used to determine whether the altered amino acid residues ( $\mathrm{K}$ replacing an $R$ and an $R$ replacing a $G$ ) formed polar contacts. A cutoff value 2.5 was used, with all possible atomic contacts occurring within this range being taken into consideration (Fig. 3A). Figure 2A shows that the mutated residues are capable of forming at least 3 minimum polar interactions. To determine whether the mutated residues formed stronger contacts than the wild type ones $(R, G)$, the same step was repeated for them. Only 1 hydrogen bond (Fig. 3B) was observed at this cutoff value, indicating the mutated residues displayed stronger polar interaction with the $M$ protein than the wild type residues.

\section{Discussion}

Our primary research question was whether the two $\mathrm{N}$ protein variants in focus alter the protein's interactions with the $M$ protein. To that end, we highlighted two major observations that can hold potential significance. The first is the supposed temperature sensitivity of the mutant $\mathrm{N}$ protein. This would seem to indicate that the mutations may be of a disadvantageous nature. An $\mathrm{N}$ protein that is adversely affected by increased temperatures may be more vulnerable to having its bonds with the $M$ proteins disrupted by increased heat. The end result could be a loss of viral transmission and survival chances in hotter climates. This is especially important given that this variant is found across the globe, including warmer regions [26]. Secondly, the gain of a salt bridge can potentially strengthen the N-M protein interactions for the mutant. Given the importance of this interaction to virion structure, this could theoretically further stabilize the nucleocapsid. In addition, the salt bridges for the wild type involved only one residue on the $M$ protein (the lysine at position 162). In contrast, the mutant protein interacts with three separate residues on the $M$ protein through salt bridges. These are ARG42, ARG146 and ARG150. The strengthened interaction theory is further backed up by the fact that the mutant had more potential hydrogen bonds and more potential Van der Waal's interactions with the $M$ protein. An important caveat here is that in all of these cases, the atomic distances between the interacting atoms was over $2.5 \AA$. The average length of a hydrogen bond is taken to be $2-2.5 \AA$. This would seem to call the existence of these hydrogen bonds into question somewhat. However, this does give even more importance to the higher number of salt bridges for the mutant protein, as they may potentially be creating a more stable complex with the $\mathrm{M}$ protein. 
Table 2 Residues involved in hydrogen bonds and salt bridges between the wild type $\mathrm{N}$ protein and the $\mathrm{M}$ protein

\begin{tabular}{|c|c|c|c|c|c|c|c|}
\hline Bond type & $\begin{array}{l}\text { M protein } \\
\text { atom }\end{array}$ & $\begin{array}{l}\text { M protein } \\
\text { residue }\end{array}$ & $\begin{array}{l}\text { M protein residue } \\
\text { position }\end{array}$ & $\begin{array}{l}\mathrm{N} \text { protein } \\
\text { atom }\end{array}$ & $\begin{array}{l}\mathrm{N} \text { protein } \\
\text { residue }\end{array}$ & $\begin{array}{l}\mathrm{N} \text { protein residue } \\
\text { position }\end{array}$ & Distance \\
\hline Hydrogen bond & OD2 & ASP & 3 & OG & SER & 318 & 2.83 \\
\hline Hydrogen bond & ND2 & ASN & 41 & $\mathrm{O}$ & SER & 310 & 2.81 \\
\hline Hydrogen bond & ND2 & ASN & 41 & $\mathrm{O}$ & ALA & 311 & 2.88 \\
\hline Hydrogen bond & $\mathrm{NE}$ & ARG & 42 & $\mathrm{O}$ & PHE & 315 & 2.83 \\
\hline Hydrogen bond & $\mathrm{NH} 2$ & ARG & 42 & $\mathrm{O}$ & PHE & 315 & 2.69 \\
\hline Hydrogen bond & $\mathrm{NH} 2$ & ARG & 42 & $\mathrm{O}$ & GLY & 316 & 2.67 \\
\hline Hydrogen bond & NE & ARG & 44 & OE1 & GLN & 306 & 3.17 \\
\hline Hydrogen bond & $\mathrm{NH} 2$ & ARG & 44 & OE1 & GLN & 306 & 2.69 \\
\hline Hydrogen bond & $\mathrm{NH} 2$ & ARG & 44 & OG & SER & 312 & 2.77 \\
\hline Hydrogen bond & $\mathrm{NE}$ & ARG & 101 & OE1 & GLN & 390 & 2.8 \\
\hline Hydrogen bond & $\mathrm{NH} 1$ & ARG & 101 & OE1 & GLN & 386 & 2.67 \\
\hline Hydrogen bond & $\mathrm{NH} 1$ & ARG & 101 & OE1 & GLN & 389 & 2.77 \\
\hline Hydrogen bond & $\mathrm{NH} 2$ & ARG & 101 & OE1 & GLN & 389 & 2.75 \\
\hline Hydrogen bond & $\mathrm{NH} 2$ & ARG & 101 & OE1 & GLN & 390 & 2.8 \\
\hline Hydrogen bond & $\mathrm{NH} 1$ & ARG & 158 & $\mathrm{O}$ & LEU & 339 & 2.67 \\
\hline Salt bridge & $\mathrm{NZ}$ & LYS & 162 & OD1 & ASP & 341 & 2.69 \\
\hline Salt bridge & $\mathrm{NZ}$ & LYS & 162 & OD2 & ASP & 348 & 2.56 \\
\hline
\end{tabular}

Other studies have also highlighted this variant and the two resultant amino acid substitutions as potentially destabilizing the protein structure [3]. These have suggested viruses containing these variants may be less adept at transmission, owing to the conserved nature of this region of the protein $[12,23,28,29]$. This agrees with our temperature sensitivity analysis, although the additional salt bridges we predicted would seem to contradict this.

How these additional interactions and the resulting stronger nucleocapsid structure could impact virion transmission and pathogenesis is an area that should be targeted by future research. These findings do make for difficult interpretation in terms of the original question we posed. The potential for the 28881-28883 variant to enhance pathogenic potential of the virus is still very much a possibility. Moreover, this MNV is now distributed globally, suggesting

Table 3 The affinity for the mutant and wild type $\mathrm{N}$ proteins for the $\mathrm{M}$ protein at 25 and $35^{\circ} \mathrm{C}$. As it can be seen, the mutant appears to display more temperature sensitivity than the wild type, with its affinity for the $\mathrm{M}$ protein decreasing over this range

\begin{tabular}{lll}
\hline Protein & Temperature $\left({ }^{\circ} \mathbf{C}\right)$ & $\begin{array}{l}\text { Affinity for } \mathbf{M} \\
\text { protein }(\mathbf{M})\end{array}$ \\
\hline Mutant isolate N protein & 25 & $5.30 \mathrm{E}-11$ \\
& 35 & $1.10 \mathrm{E}-10$ \\
Wuhan virus N protein & 25 & $1.30 \mathrm{E}-09$ \\
& 35 & $2.50 \mathrm{E}-09$ \\
\hline
\end{tabular}

this may have been an advantageous variant that became stably integrated into the genome over time.

Regardless of how severe the symptoms of infection are, a more stable virus will be able to survive for longer and infect more people. The real effect of the changes in salt bridge bonds is of course something that needs to be confirmed and determined by experimental evidence. One major factor behind throwing that into doubt is the fact that while the number of bridges was more for the mutant protein, the participating atoms were further apart compared to the two salt bridges for the wild type.

As the battle against SARS-CoV-2 continues to complicate, it becomes important for the research community to once more pay close attention to the fundamental aspects of the virus. The more practical consequences of this variant, such as vaccine effectiveness, remains difficult to ascertain. The ones that do not rely on detection of $\mathrm{N}$ protein components, such as the BNT162b1 or ChAdOx1 nCoV-19 vaccines (both Spike protein reliant), should not theoretically be affected. However, if future vaccines choose to use the $\mathrm{N}$ protein for eliciting an immune reaction, then this could change. The nature of the impact demands future investigation [10].

\section{Conclusions}

We believe there is evidence to suggest that the SARSCoV-2 isolates harbouring the 28881-28883 mutation have the potential to increase stability of the viral nucleocapsid. This interpretation is derived from the gain 


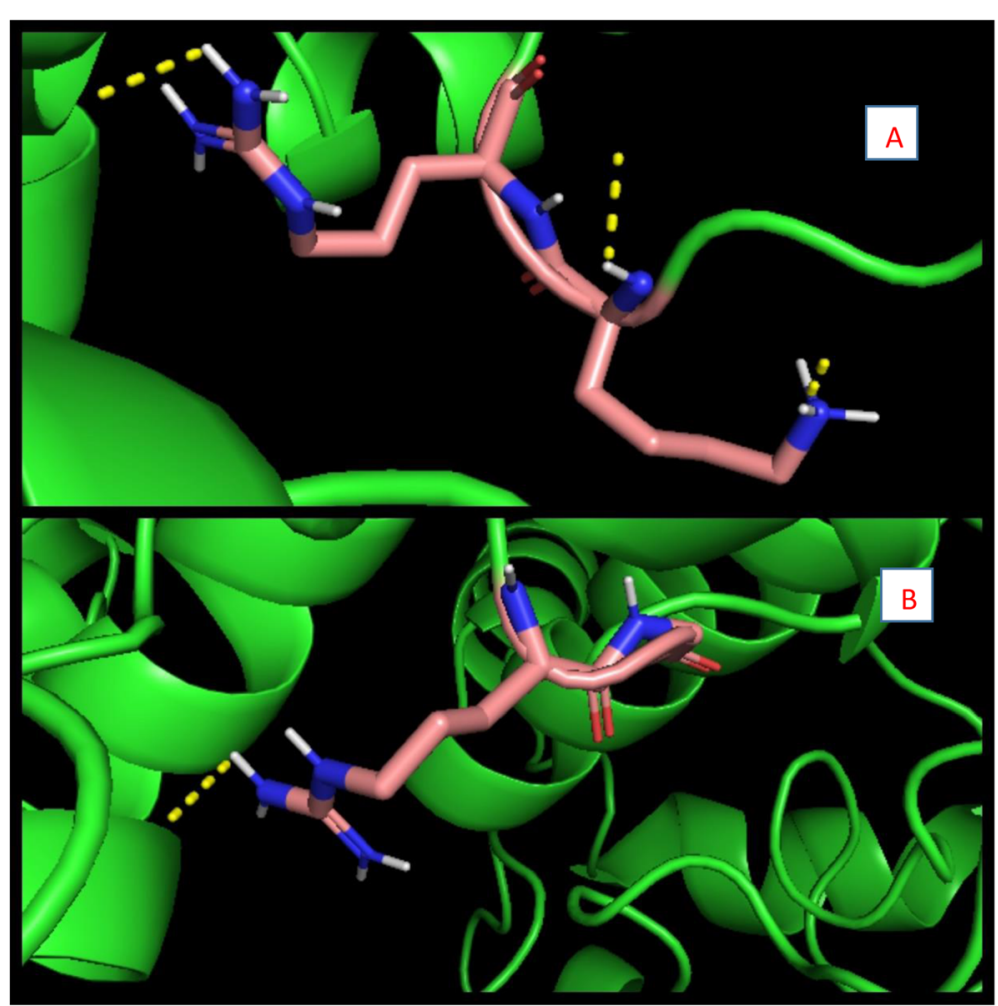

Fig. 3 A Determination of Hydrogen bonds over $2.5 \AA$ for the mutated residues, using Pymol. Mutated residues shown as sticks (atoms: nitrogenblue, carbon-pink, hydrogen-white), N protein in green and hydrogen bonding as yellow dots. B Determination of hydrogen bonds over a $2.5 \AA$ range for wild type residues. Original wild type residues shown as sticks (atoms: nitrogen-blue, carbon-pink, hydrogen-white, oxygen-red), $\mathrm{N}$ protein in green and hydrogen bonding as yellow dots

of certain amino acid interactions that may strengthen its complex with the viral $\mathrm{M}$ protein, potentially leading to a more stable virus structure. Though causality cannot yet be established, this does nonetheless deserve further investigation with regards to its potential impact on viral survival and transmission.

\section{Abbreviations}

MNV: Multiple nucleotide variant; SARS-CoV-2: Severe acute respiratory syndrome coronavirus 2; N protein: Nucleocapsid protein; M protein: Membrane protein; LLPS: Liquid-liquid phase separation

\section{Supplementary informations}

The online version contains supplementary material available at https://doi. org/10.1186/s43141-021-00233-z.

Additional file 1: Supplementary Table 1A. - Complete list of closely situated residues from mutant $\mathrm{N}$ protein and $\mathrm{M}$ protein in the docked complex.

Additional file 2: Supplementary Table 1B. - Complete list of closely situated residues from wild type $\mathrm{N}$ protein and $\mathrm{M}$ protein in the docked complex.

Additional file 3: Supplementary File 1. - Docked complex between mutant $\mathrm{N}$ protein and $\mathrm{M}$ protein.

Additional file 4: Supplementary File 2. - Docked complex between wild type $\mathrm{N}$ protein and $\mathrm{M}$ protein.
Acknowledgements

Not applicable.

Authors' contributions

SQ carried out the protein structure prediction, refinement and docking. SH designed the workflow. SQ and SH prepared the manuscript. All authors have read and approved the manuscript.

Funding

Not applicable

Availability of data and materials

No new genomic or proteomic sequences were generated through this study. The in silico predicted structures are made available in the supplementary material.

\section{Declarations}

Ethics approval and consent to participate Not applicable

Consent for publication

Not applicable.

Competing interests

The authors declare no conflict of interest. 
Received: 5 March 2021 Accepted: 21 August 2021

Published online: 20 September 2021

\section{References}

1. Abdool Karim S, de Oliveira T (2021) New SARS-CoV-2 variants - clinical, public health, and vaccine implications. New England Journal of Medicine. 384(19):1866-1868. https://doi.org/10.1056/nejmc2100362

2. Ahmed W, Philip A M, Biswas K H (2021) Stable interaction of the UK B.1.1.7 lineage SARS-CoV-2 S1 spike N501Y mutant with ACE2 revealed by molecular dynamics simulation

3. Azad G (2021) The molecular assessment of SARS-CoV-2 Nucleocapsid Phosphoprotein variants among Indian isolates. Heliyon 7(2):e06167. https:// doi.org/10.1016/j.heliyon.2021.e06167

4. Armstrong J, Niemann H, Smeekens S, Rottier P, Warren G (1984) Sequence and topology of a model intracellular membrane protein, E1 glycoprotein, from a coronavirus. Nature 308(5961):751-752. https://doi.org/10.1038/3 $08751 \mathrm{a0}$

5. Bhadra A, Singh S, Chandrakar S, Kumar V, Sakshi S, Sayuj Raj T, Selvarajan E (2020) Current clinical trials and vaccine development strategies for corona virus disease (COVID-19). J. Pure Appl. Microbiol:979-988. https://doi.org/1 0.22207/JPAM.14.SPL1.36

6. Bhattacharya D, Nowotny J, Cao R, Cheng J (2016) 3Drefine: an interactive web server for efficient protein structure refinement. Nucleic Acids Research 44(W1):W406-W409. https://doi.org/10.1093/nar/gkw336

7. Chang C, Sue S, Yu T et al (2005) Modular organization of SARS coronavirus nucleocapsid protein. J Biomed Sci 13(1):59-72. https://doi.org/10.1007/s113 73-005-9035-9

8. Cubuk J, Alston J, Incicco J et al (2021) The SARS-CoV-2 nucleocapsid protein is dynamic, disordered, and phase separates with RNA. Nat Commun 12(1):1936. https://doi.org/10.1038/s41467-021-21953-3

9. Datta S (2019) A systematic study on the recent crisis in public health in Kerala. Asian J Health Sci 5(1):5-5. https://doi.org/10.15419/ajhs.v5i1.444

10. Dong Y, Dai T, Wei Y, Zhang L, Zheng M, Zhou F (2020) A systematic review of SARS-CoV-2 vaccine candidates. Signal Transduct Target Ther 5(1):237. https://doi.org/10.1038/s41392-020-00352-y

11. El Idrissi HH (2020) COVID-19: What you need to know. Gene Rep 20: 100756. https://doi.org/10.1016/j.genrep.2020.100756

12. Garvin M, Prates ET, Pavicic M et al (2020) Potentially adaptive SARS-CoV-2 mutations discovered with novel spatiotemporal and explainable Al models. Genome Biol 21(1):304. https://doi.org/10.1186/s13059-020-02191-0

13. Heo L, Park H, Seok C (2013) GalaxyRefine: protein structure refinement driven by side-chain repacking. Nucleic Acids Res 41(W1):W384-W388. https://doi.org/10.1093/nar/gkt458

14. Junejo Y, Ozaslan M, Safdar M, Khailany RA, Rehman S, Yousaf W, Khan MA (2020) Novel SARS-CoV-2/COVID-19: origin, pathogenesis, genes and genetic variations, immune responses and phylogenetic analysis. Gene Rep 20: 100752. https://doi.org/10.1016/j.genrep.2020.100752

15. Kakhki RK, Kakhki MK, Neshani A (2020) COVID-19 target: a specific target for novel coronavirus detection. Gene Rep 20:100740. https://doi.org/10.1016/j. genrep.2020.100740

16. Kalantari H, Tabrizi A, Foroohi F (2020) Determination of COVID-19 prevalence with regards to age range of patients referring to the hospitals located in western Tehran, Iran. Gene Rep 21:100910. https://doi.org/10.101 6/j.genrep.2020.100910

17. Khailany RA, Safdar M, Ozaslan M (2020) Genomic characterization of a novel SARS-CoV-2. Gene Rep 19:100682. https://doi.org/10.1016/j.genrep.2020.100682

18. Kim D, Chivian D, Baker D (2004) Protein structure prediction and analysis using the Robetta server. Nucleic Acids Res 32:W526-W531. https://doi. org/10.1093/nar/gkh468

19. Kozakov D, Hall D, Xia B et al (2017) The ClusPro web server for proteinprotein docking. Nat Protoc 12(2):255-278. https://doi.org/10.1038/nprot.201 6.169

20. Lan J, Ge J, Yu J, Shan S, Zhou H, Fan S, Zhang Q, Shi X, Wang Q, Zhang L, Wang $X$ (2020) Structure of the SARS-CoV-2 spike receptor-binding domain bound to the ACE2 receptor. Nature 581(7807):215-220. https://doi.org/10.1 038/s41586-020-2180-5

21. Laskowski R, Jabłońska J, Pravda L et al (2017) PDBsum: structural summaries of PDB entries. Protein Sci 27(1):129-134. https://doi.org/10.1002/pro.3289

22. Mahmoud DB, Shitu Z, Mostafa A (2020) Drug repurposing of nitazoxanide: can it be an effective therapy for COVID-19? J Genet Eng Biotechnol 18(1): 1-10. https://doi.org/10.1016/j.genrep.2020.100910
23. Rahman M, Islam M, Alam A et al (2020) Evolutionary dynamics of SARSCoV-2 nucleocapsid protein and its consequences. J Med Virol 93(4):21772195. https://doi.org/10.1002/jmv.26626

24. Rouchka E, Chariker J, Chung D (2020) Variant analysis of 1,040 SARS-CoV-2 genomes. PLoS One 15(11):e0241535. https://doi.org/10.1371/journal.pone. 0241535

25. Saha O, Hossain MS, Rahaman MM (2020) Genomic exploration light on multiple origin with potential parsimony-informative sites of the severe acute respiratory syndrome coronavirus 2 in Bangladesh. Gene Rep 21: 100951. https://doi.org/10.1016/j.genrep.2020.100951

26. Ugurel O, Ata O, Turgut-Balik D (2020) An updated analysis of variations in SARS-CoV-2 genome. Turk J Biol 44(3):157-167. https://doi.org/10.3906/biy-2 005-111

27. Vangone A, Spinelli R, Scarano V, Cavallo L, Oliva R (2011) COCOMAPS: a web application to analyze and visualize contacts at the interface of biomolecular complexes. Bioinformatics 27(20):2915-2916. https://doi.org/1 0.1093/bioinformatics/btr484

28. Wang J, Shi C, Xu Q, Yin H (2021a) SARS-CoV-2 nucleocapsid protein undergoes liquid-liquid phase separation into stress granules through its $\mathrm{N}$ terminal intrinsically disordered region. Cell Discov 7(1):5. https://doi.org/1 0.1038/s41421-020-00240-3

29. Wang R, Chen J, Gao K, Hozumi Y, Yin C, Wei GW (2021 b) Analysis of SARSCoV-2 mutations in the United States suggests presence of four substrains and novel variants. Commun Biol 4(1):228. https://doi.org/10.1038/s42003021-01754-6

30. WHO Coronavirus (COVID-19) Dashboard. In: Covid19.who.int https://covid1 9.who.int/. Accessed 21 Apr 2021

31. Xue L, Rodrigues J, Kastritis P et al (2016) PRODIGY: a web server for predicting the binding affinity of protein-protein complexes. Bioinformatics. https://doi.org/10.1093/bioinformatics/btw514

\section{Publisher's Note}

Springer Nature remains neutral with regard to jurisdictional claims in published maps and institutional affiliations.

\section{Submit your manuscript to a SpringerOpen ${ }^{\circ}$ journal and benefit from:}

- Convenient online submission

- Rigorous peer review

- Open access: articles freely available online

- High visibility within the field

- Retaining the copyright to your article

Submit your next manuscript at $>$ springeropen.com 